\title{
Generic Production System Model of Personalized Production
}

\author{
Petra Foith-Förster ${ }^{1, *}$ and Thomas Bauernhansl ${ }^{1,2}$ \\ ${ }^{1}$ Fraunhofer Institute for Manufacturing Engineering and Automation IPA, Nobelstr. 12, 70569 Stuttgart, Germany \\ ${ }^{2}$ Institute of Industrial Manufacturing and Management, Allmandring 35, 70569 Stuttgart, Germany
}

\begin{abstract}
Manufacturing companies are operating in a turbulent business ecosystem that calls for product variety, product mix flexibility, volume scalability and high efficiency. Personalized production arises as new production paradigm to replace mass personalization. The paper proposes a generic model for the design of production systems for the paradigm of personalized production. The model applies the system design methodology Axiomatic Design and uses the notation of Axiomatic Design Theory for Systems combined with the product precedence graph for product structure modeling. The model represents the static system structure, decomposed into its subsystems, and explains the dynamic behavior of the system during operation, depending on the product's architecture. It is intended as a reference model for production system planning.
\end{abstract}

\section{Introduction}

The diversification of globalized markets and the increasing customer demand for individualization, together with a turbulent operative ecosystem have led to a fierce business environment for manufacturing companies [1-2]. The coupled production lines of mass customization with their limited variant flexibility and volume scalability are not a competitive production system setup to meet these requirements. Instead, flexible and reconfigurable manufacturing systems (RMS) for a personalized production of individualized products in high volumes are needed [2-3].

Production systems are complex socio-technical systems $[1,4]$. Thus, it is impossible to describe them explicitly [5]. System models are a means of pragmatic simplification to the planning-relevant parts of the real system [6]. As representation of a real object, a model enables the scientific or technical description and analysis through idealization or abstraction [7]. A production system model serves as an abstract template that is adapted to case specific requirements during system design. It gives orientation to the planners, who instantiate the production system model by applying a system design method (Figure 1 for the example of a personalized production system design with the design method of Axiomatic Design). The model helps to achieve a structured design process. This paper presents a generic reference model for the design of production systems for personalized production.

Many existing production system models are too specific for general application (manufacturer-specific production system design documentations) or are representations of former production paradigms (e.g. [8-9] for customized serial production). There are production system models of reconfigurable, flexibly linked systems, but non of them offers a holistic view on the production system

*e-mail: pff@ipa.fhg.de

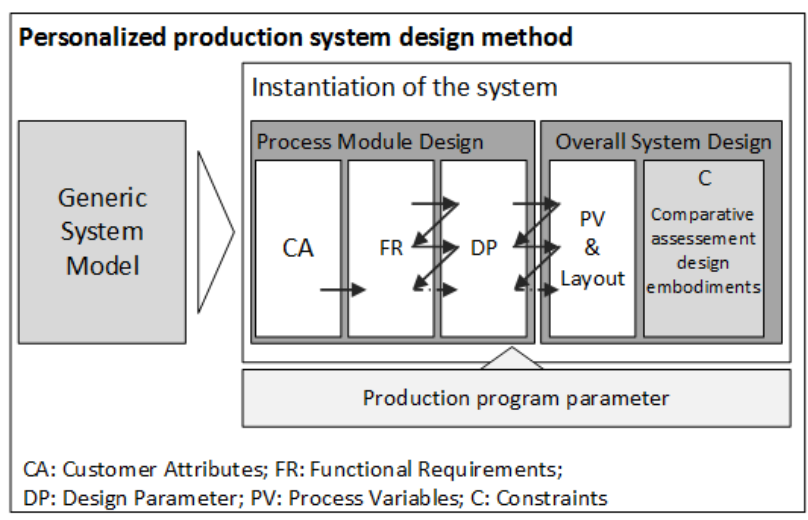

Figure 1. Role of a generic system model in production system design

level to support the design process of a personalized production system: The concept of biological manufacturing systems (BMS) [10-11] proposes line less production systems, in which all of its autonomous and self-organized, structural system elements are moving to adapt to fluctuations or malfunctional machines. The concept puts no specific focus on the design of different functional requirements of different variants. The moved objects make BMS very complex and they have never been implemented outside of case studies. Koren et al. [12] model RMS and develop methods and algorithms on how to configure RMS. They define a structure of similar machines ordered in stages. Albeit reconfigurable assembly systems are addressed also, their main focus is on machining. Manns et al. [13] transfer tht RMS concepts to assembly, but similarly only put focus on the optimal topology of the layout configuration (serial, parallel, bypass, grid) and don't offer an overall system model. Kern et al. [14-16] suggest a modular assembly system with flexible routing between decoupled stations for the automotive industry. In their 


\begin{tabular}{|c|c|c|c|c|c|}
\hline Product & $\begin{array}{l}\text { Job Shop } \\
\text { Production } \\
\text { Pros }\end{array}$ & $\begin{array}{l}\text { Workbench } \\
\text { Fabrication }\end{array}$ & $\begin{array}{l}\text { Building } \\
\text { Site } \\
\text { Production }\end{array}$ & $\begin{array}{l}\text { Production } \\
\text { Group }\end{array}$ & 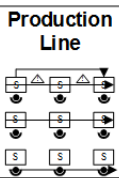 \\
\hline $\begin{array}{l}\text { Typification } \\
\text { eed criteria } \\
\text { ect }\end{array}$ & $\begin{array}{c}\text { Manu- } \\
\text { facturing } \\
\text { Technology }\end{array}$ & Worker & Product & $\begin{array}{r}\text { Proc } \\
\text { archite } \\
\text { of far }\end{array}$ & $\begin{array}{l}\text { Product } \\
\text { architecture } \\
\text { of variants }\end{array}$ \\
\hline s & stationary & oving & moving & mov & $\begin{array}{l}\text { stationary } \\
\text { or moving }\end{array}$ \\
\hline & stationary & & moving & stati & nary \\
\hline & ving & ain & stationary & & \\
\hline
\end{tabular}

Figure 2. Common organizational structures [18, 22, 23]

production system model, every functional station type only exists exactly once. The functional segmentation of work content between different stations is oriented along the product architecture and its assembly sequence, essentially building a decoupled assembly line with bypasses. This is suitable for the highly standardized product architectures of automobiles, but not sufficient for personalized production and the integration of future variants with possibly different product architecture.

\section{Production system models}

To identify the relevant components of the model, understanding the design object is crucial. The focus of this paper lies on the design of the system structure. Manufacturing process planning is not within the scope. A production system executes the transformation of production factors into produced goods [17-18]. In a narrow technical understanding, this transformation implies the direct product generating actions of value added manufacturing and assembly processes and the material flow [19]. Generally, a system is a set $S=\{E, F, B\}$ of elements $E$, functions $\mathrm{F}$ and relations $\mathrm{B}$ between the elements [20]. The elements of a production system are the system's subsystems, i.e. manufacturing and assembly stations or cells and logistical resources for the physical material transport [3]. In this paper, we call the elements of a personalized production system manufacturing, assembly and transport process modules.

Personalized production is associated with a pull type business model to produce individualized products in high volumes [2]. Individualized products are highly modular products with a predefined product architecture but customer-individual configuration of modules and specific customer-individual parts $[2,21]$. The respective production system needs to run an industrial production with lot size one processes. The individual product module configuration is contradictory to a linear setup of production resources connected in series. The production system needs to have a modular setup itself, allowing for an ad-hoc configuration to match production orders. Furthermore, the option of individual components in individualized products leads to an integration of both manufacturing and assembly technologies into one personalized production system.

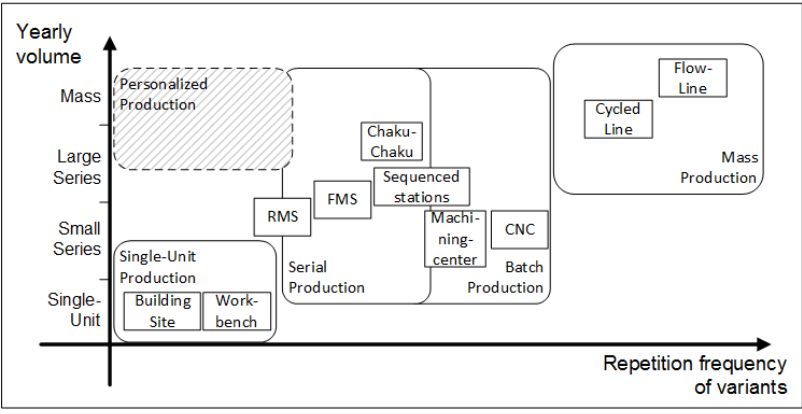

Figure 3. Production structure types related to volume and product variety (enhanced compilation of [18, 31, 33-36])

In business economics' literature, the organizational structure $[24,26]$ of production systems are categorized by the chronological, spatial and technical interaction of their production factors, i.e. workers, operating resources and materials [27]. The functional scope (technical criterium) and the movement (chronological-spatial criterium) of the system elements determine the type of organizational structure (Figure 2). The common organizational structures can be roughly assigned to the output quantity of a production system (Figure 3). When plotted over the repetition frequency of a variant (measured as number of variants of a specific part number per time unit), it is obvious that personalized production lies outside the trend line: High product variety, i.e. low repetition frequency, needs to be produced in large numbers.

There is a close relation between product and production system structure: a production process is realized by multiple successive relations of production system elements [18]. The chronological production sequence is built according to the degrees of freedom given by the product structure, i.e. which manufacturing activities are obliged to be executed after one another and which can be executed independently [28]. As such, a dynamic production system structure model needs to relate to a product structure model of produced goods.

\section{Selection of a modeling notation}

A model always uses a formal notation for its description of reality [29]. Production systems are subsystems of a business enterprise [3]. Therefore, business enterprise modeling notations can be applied for production system modeling. There are numerous enterprise modeling notations. Specker [30] groups them into a modeling matrix according to the aspects of process, function, object and task. Since it is usually not sufficient to only use one modeling aspect to built a system model [30], common integrated methods (such as the architecture of integrated information systems (ARIS), Unified Modeling Language (UML), Systems Modeling Language (SysML), Human-Technology-Organisation Analysis (MTO), Axiomatic Design (AD) Theory for Systems and members of the Integrated DEFinition language Family (IDEF) occupy several fields of the matrix (Table 1). Notations that are (also) used for product modeling are asterisked in the matrix. As a model of the physical component structure, 


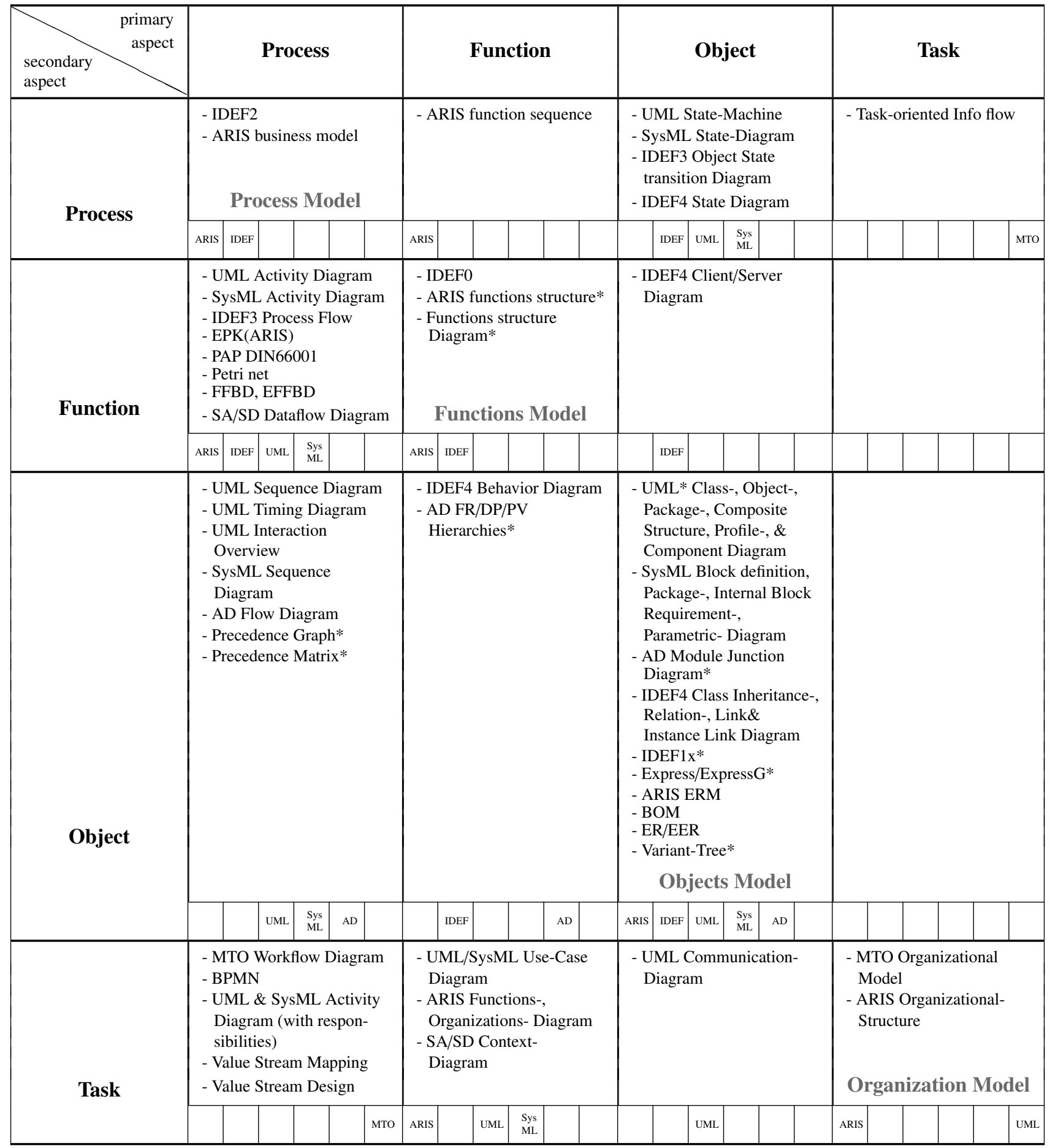

Table 1. Model notation matrix (as of [30]) filled with common business enterprise model notations

the bill of material (BOM) is a product architecture representation [31]. A precedence graph transfers this objectoriented product structure model into a process view, fitting the perspective of a production's operational behavior better [28].

To select the notation for the personalized production system reference model, the notations are compared to the specific requirements of the model:

- To ensure a stable and controllable behavior, a system (albeit being modular) needs to be planned top-down instead of merely adding subsystems and components without consideration of the entire system design [32]. The modeling notation thus needs to allow a modeling of the production system on different system levels.

- The representation must be production program neutral to ensure the reference character of the model.

- With the transformation of production factors into a product as overall functional requirement, the mod- 
eling notation must allow a functions-object mapping of product requirements to the process modules.

- Due to its implication on the system structure, the model must be able to give a product dependent process view description.

The notation must be capable of representing all system components relevant for planning. It must be possible to

- model different classes of process modules,

- attributively assign them with their functions,

- hierarchically decompose the elements into their subsystems (relations, types, multiplicity) as they bear the technical and technological functions to realize the production process,

- model possible relations of process modules to reflect the process structure of the system.

Furthermore, general characteristics for a good model (compare [20]) must be achieved. The model has to be:

- realistic: This is in line with the above formulated demand to model the system in all relevant components.

- formally correct: The model must be repeatable and verifiable. A common modeling method must be chosen so that the members of a professional community can check it for contradictions.

- purpose-oriented: It must be possible to integrate the model into a subsequent planning method for production system planning.

- practicable and of small effort: The model must be intuitively interpretable for the production planner with little prior knowledge about modeling.

In principle, it is possible to model the required generic system model with all integrated object-oriented methods introduced above. Due to the high compatibility to Axiomatic Design as a general design method of technical systems, its suitability to decompose different system levels, as well as the ability to directly express the functional requirements of the product as such, a decision is made in favor of the Axiomatic Design Theory for Systems for production system modeling (Figure 4). A process view description of the product in relation to the product system also seems possible. To facilitate the necessary analysis of the product structure, the precedence graph is additionally chosen to model the product.

Axiomatic Design Theory for Systems is based on the general planning method of Axiomatic Design which was developed by Suh [32] as a methodology to guide the design process of complex systems with two fundamental axioms: The independence axiom seeks for functional separation of functional requirements (FRs) and design parameters (DPs). According to the axiom, a design is ideal, if FRs are kept independent of each other, i.e. each DP only influences exactly one FR. In a decoupled design, there are design goals that are influenced by more than one solution parameter. A stable system can still be reached with a decoupled design, if the design solution parameters are implemented in the right order. It is impossible to reach a stable system state with a coupled design. Feedback loops between the parameters lead to unintended influences if one design solution parameter is changed. [33]

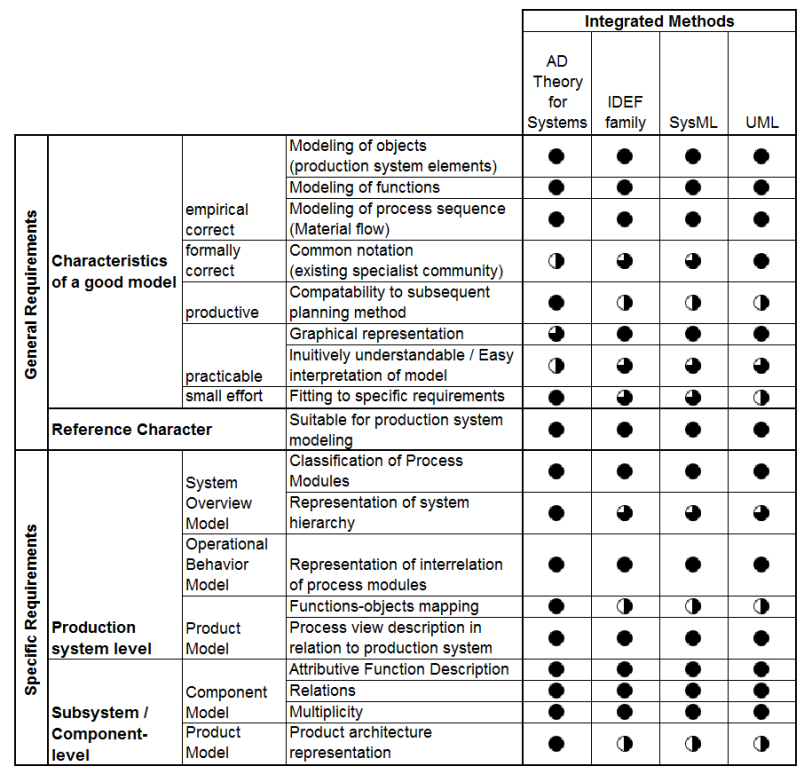

Figure 4. Comparison of model requirements and suitable integrated modeling notations

The design is detailed by decomposing each DP hierarchically into the next layer of FRs, until an implementable design stage is reached. The FR-DP mapping is illustrated as FR-DP-design tree or design matrix. [33]

The information axiom delivers a decision-making principle between alternative DPs by judging on its probability to successfully satisfy a respective requirement. The best design is considered the one with the least information content (I). [33]

This paper designs a generic reference model. Selected DPs of the model are placeholders, to be replaced by actual DPs when the model is applied and adapted during the design of a personalized production system. The information content can, however, only be computed with quantified system ranges. Consequently, the information axiom is of minor importance to the production system reference model.

In addition to FRs, superordinate requirements, called constraints (C), set bound to the possible space of acceptable solutions. Cost is a typical input $\mathrm{C}$, whereas higher level DPs act as system constraints to all its lower layers. Usually, the design needs to be completed before it can be checked regarding its Cs. [32]

Axiomatic Design Theory for Systems supplies further diagrams to illustrate a system: the module junction diagram gives the interrelationship between modules in a system design. In the notation of Axiomatic Design, modules are rows of FR-DP mappings. They may or may not correspond to actual physical modules of the production system design. A module junction diagram represents the functions structure of a system. The flow diagram illustrates the dynamic behavior of the system during operation. The system control command, which is the rule for the execution of the system architecture, is derived from the system flow chart. [32] 


\section{Reference model}

The reference model comprises three sections: In the first section, a general system segmentation explains the fundamental structure of a personalized production system. In the second section, the hierarchical decomposition defines generic process modules as the production system elements, allocates functions, and builds the generic process module architecture. The third section contains the flow chart of the personalized production system, modeling the process structure of the system during operation, depending on the products produced.

\subsection{General system segmentation}

The key functional requirement of a personalized production system design is to produce individualized products at the cost of serial production. On the subsequent two levels of the FR-DP hierarchy, the production system is segmented into a conventional manufacturing system and a production subsystem for personalization (Figure 5). An intralogistics system connects those two subsystems.

The conventional manufacturing subsystem is designated only to those manufacturing technologies that are not capable of efficient single unit production. Consequently, this production segment produces parts that are not customized.

The hierarchy further decomposes the personalized production system, which contains manufacturing and assembly process modules capable of lot-size-one production, as well as transport modules to connect those value added modules. Its focus is set on the personalization of products as demanded by the customer. Manufacturing and assembly technologies are thus integrated in one production system segment.

Equations 1 and 2 give the design matrices of the segmentation hierarchy. They are designed as decoupled matrices: Manufacturing of parts always precedes assembly, making assembly, in general, dependent on manufacturing. Material transport is only performed when needed to enable the value added processes and is designed as a process, dependent on both manufacturing and assembly.

$$
\begin{aligned}
\left\{\begin{array}{l}
F R_{1} \\
F R_{2} \\
F R_{3}
\end{array}\right\} & =\left[\begin{array}{lll}
x & 0 & 0 \\
x & x & 0 \\
x & x & x
\end{array}\right]\left\{\begin{array}{l}
D P_{1} \\
D P_{2} \\
D P_{3}
\end{array}\right\} \\
\left\{\begin{array}{ll}
F R_{21} \\
F R_{22}
\end{array}\right\} & =\left[\begin{array}{ll}
x & 0 \\
x & x
\end{array}\right]\left\{\begin{array}{l}
D P_{21} \\
D P_{22}
\end{array}\right\}
\end{aligned}
$$

The input constraints for the overall system must match the general system characteristics of competitive, flexible and reconfigurable production systems of personalized production. They are accordingly formulated as:

CR1: Maximize changeability

CR2: Maximize performance

\subsection{System decomposition and process module structure}

\subsubsection{System decomposition}

To build a useful model for the design of personalized production systems, the general system segmentation is further decomposed (Figure 6). Level three of the FR-DP design tree details the value added and transport processes into process modules:

$$
\begin{aligned}
& \text { manufacturing and assembly processes } \\
& F R_{211}=\text { produce individual parts of similar process } \\
& \text { requirements (type 211) } \\
& F R_{212}=\text { produce individual parts of similar process } \\
& \text { requirements (type 212) } \\
& F R_{21 n}=\text { produce individual parts of similar process } \\
& \text { requirements (type 21n) } \\
& D P_{211}=\text { manufacturing process type } 211 \\
& D P_{212}=\text { manufacturing process type } 212 \\
& \stackrel{\sim}{D P_{21 n}}=\text { manufacturing process type } 21 \mathrm{n} \\
& F R_{21(n+1)}=\text { assemble parts and modules of sim- }
\end{aligned}
$$

\section{transport processes}

$F R_{221}=$ transport parts and sub-assemblies between value added process modules considering transportation requirements (type 221)

$$
\begin{array}{ll}
F R_{22 x}= & \begin{array}{l}
\text { transport parts and sub-assemblies be- } \\
\text { tween value added process modules } \\
\text { of similar transportation requirements } \\
\text { (type 221) }
\end{array} \\
D P_{221}= & \text { transportation process type } 221 \\
\cdots & \\
D P_{22 x}= & \text { transportation process type } 22 \mathrm{x}
\end{array}
$$
tween value added process modules of similar transportation requirements

with $n, m, x \in \mathbb{N}$.

Each FR represents a cluster of process requirements, associated to product features. Each DP represents a respective manufacturing, assembly or transport process to realize this requirement. Equation 3 gives the common design matrix of the personalized production system's decomposition. The idealized architecture promotes 


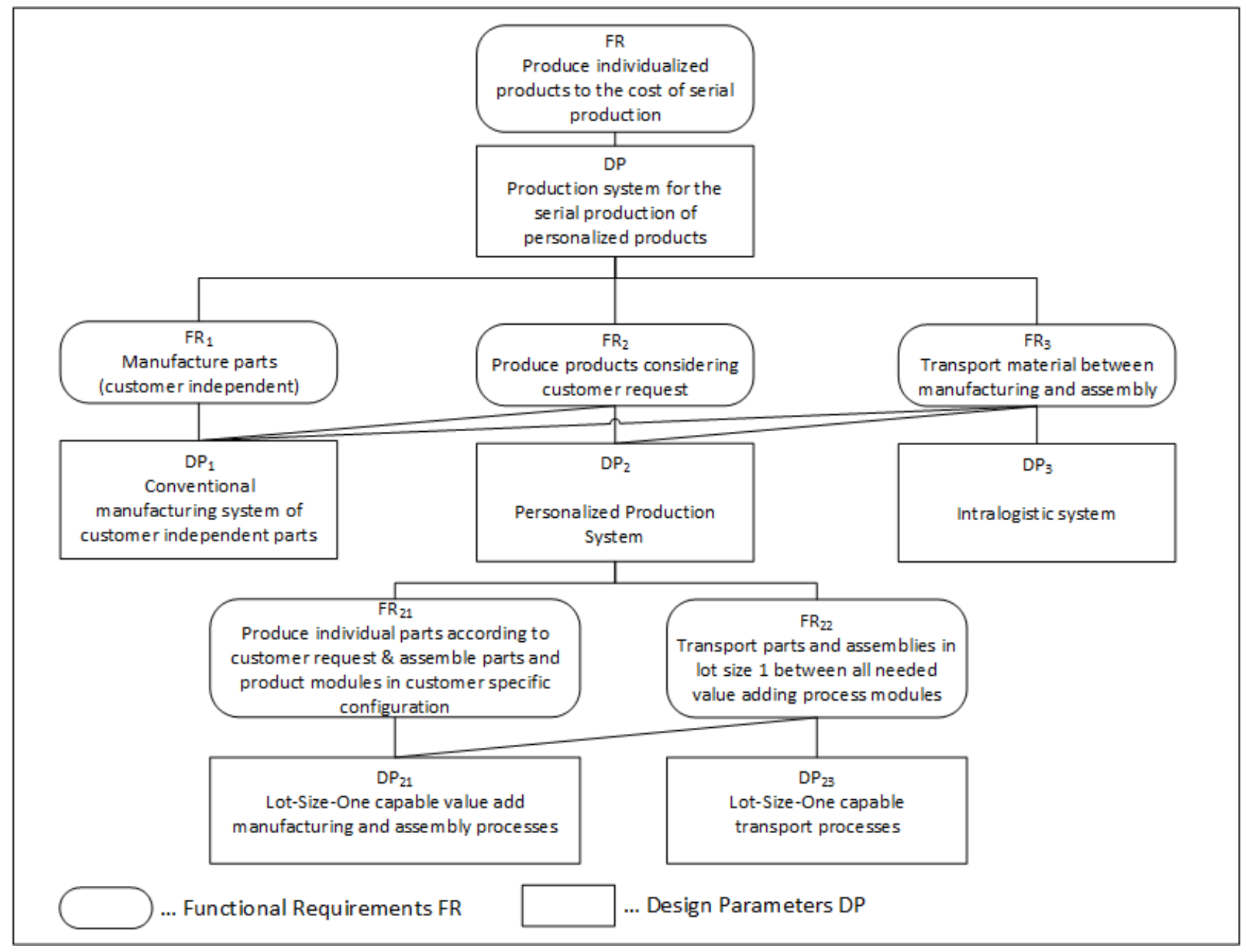

Figure 5. General system segmentation of personalized production systems

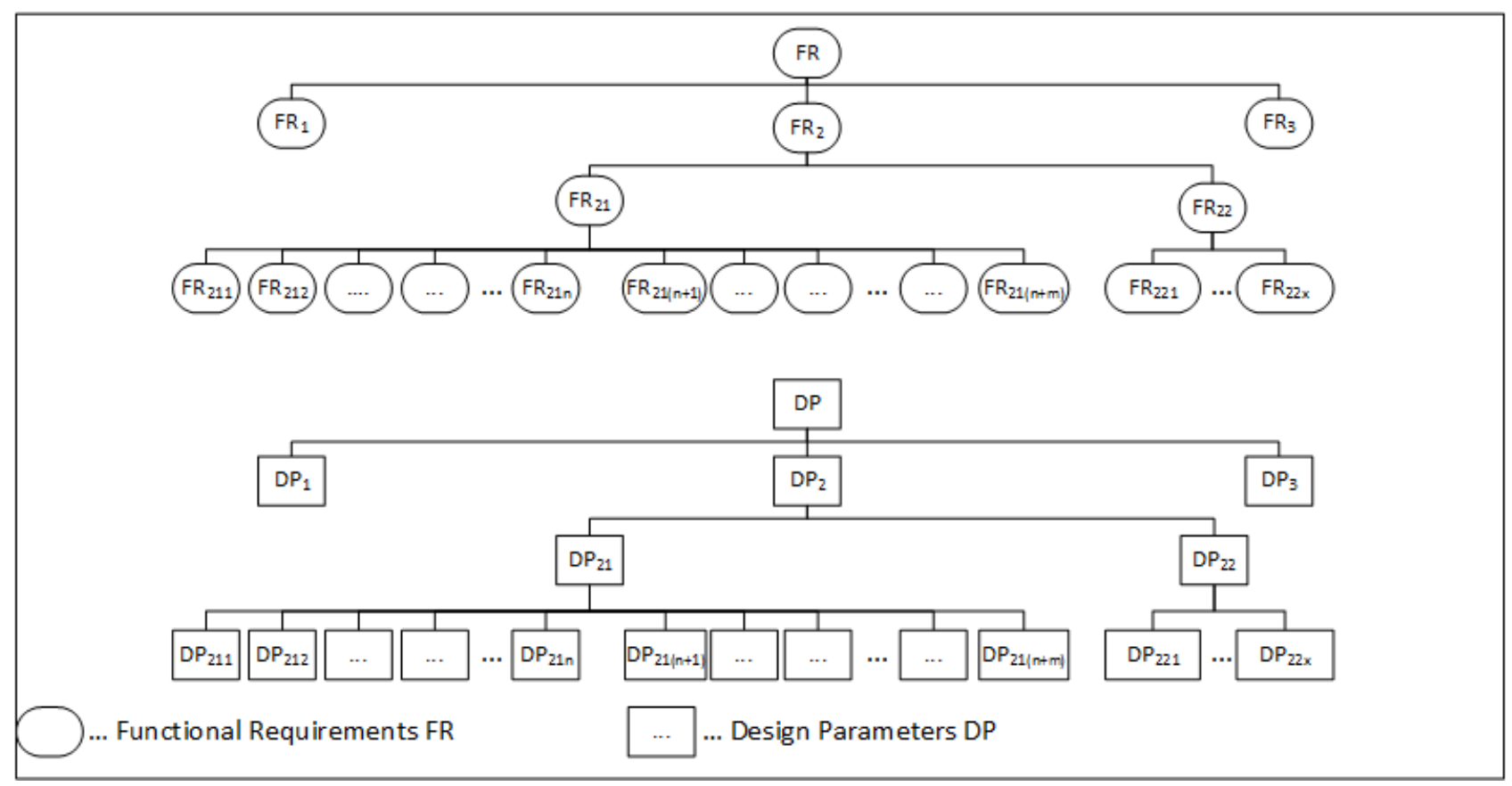

Figure 6. Decomposition of personalized production systems down to process module level 


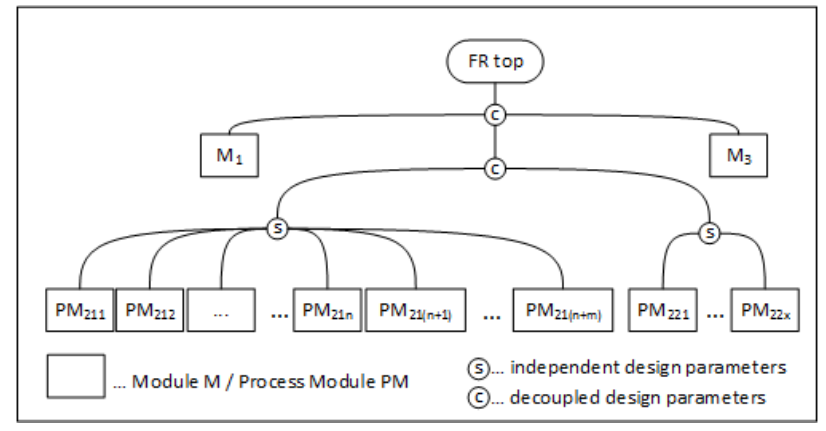

Figure 7. System structure of personalized production system

an uncoupled design within the classes of manufacturing, assembly and transport processes: This means a clear oneto-one mapping of a process type to a cluster of process requirements, associated to by product features, in this idealized model. This makes it easier to control the system during planning and operation. Sub-process steps are performed independent of each other by processes only coupled through transport when required, as long as there is no functional necessity (e.g. technological constraints) to couple them.

When being built, a product needs to go through a sequence of manufacturing and assembly processes. The respective coupling of these value added processes is realized by transport processes. The actual coupling of transport processes with value added processes in the model design matrix of equation 3 is chosen arbitrary for illustration. Each coupling represents the functional capability of a transport process to build a material flow to or from the coupled value added process modules. This depends on the state of parts or sub-assemblies that have to match the transport process' abilities. Ideally, there is only one type of transport process needed, resulting in one universal transport process module. The

The decoupled design matrix expresses the design decision that the transportation of parts is affected by both the transport and manufacturing or assembly process, but manufacturing and assembly is actually not affected by the transport process. Any subsequent design must follow this decision to prevent time dependent complexity ${ }^{1}$.

$\left\{\begin{array}{c}F R_{211} \\ \ldots \\ F R_{21(n+1)} \\ \cdots \\ \ldots \\ F R_{221} \\ \ldots \\ F R_{22 x}\end{array}\right\}=\left[\begin{array}{cccccccc}x & 0 & 0 & 0 & 0 & 0 & 0 & 0 \\ 0 & x & 0 & 0 & 0 & 0 & 0 & 0 \\ 0 & 0 & x & 0 & 0 & 0 & 0 & 0 \\ 0 & 0 & 0 & x & 0 & 0 & 0 & 0 \\ 0 & 0 & 0 & 0 & x & 0 & 0 & 0 \\ x & x & x & 0 & 0 & x & 0 & 0 \\ 0 & 0 & 0 & x & x & 0 & x & 0 \\ 0 & 0 & 0 & 0 & 0 & x & x & x\end{array}\right]\left\{\begin{array}{c}D P_{211} \\ \ldots \\ D P_{21(n+1)} \\ \ldots \\ \ldots \\ D P_{221} \\ \ldots \\ D P_{22 x}\end{array}\right\}$

The overall system structure model of the personalized production system is constructed directly from the decom-

\footnotetext{
${ }^{1}$ Axiomatic Design defines complexity as a measure of uncertainty in achieving the specified FRs. For further details and an example for time dependent combinatorial complexity see [37].
}

position as a module-junction diagram (Figure 7). Modules $M_{1}$ and $M_{3}$ represent the conventional manufacturing and intralogistics system of the $F R_{1}-D P_{1}$ and $F R_{3}-D P_{3}$. Modules $M_{21}$ and $M_{22}$ similarly group manufacturing and assembly, as well as transport processes, that are capable of single unit production. Modules $P M_{211}$ to $P M_{22 x}$ finally represent the process modules of the personalized production system, who realize the processes as defined by the third level decomposition of the production system:

\section{manufacturing and assembly process modules}

$P M_{211}=$ manufacturing process module type 21

$P M_{212}=$ manufacturing process module type 22

...

$P M_{21 n}=$ manufacturing process module type $2 \mathrm{n}$

$P M_{21(n+1)}=$ assembly process module type $2(\mathrm{n}+1)$

...

$P M_{21(n+m)}=$ assembly process module type $2(\mathrm{n}+\mathrm{m})$

\section{transport process modules}

$P M_{221}=$ transport process modules type $2(\mathrm{n}+\mathrm{m}+1)$

...

$P M_{22 x}=$ transport process modules type $2(\mathrm{n}+\mathrm{m}+\mathrm{x})$

with $n, m, x \in \mathbb{N}$.

In line with corollary 2 of Axiomatic Design to minimize the number of FRs [32], the integration of a broad functional range of product feature induced process requirements should be pursued as a cluster in one $F R$ of the personalized production system level, so that the overall number of process module types $P M$ is also reduced. This in turn has a positive impact on the efficiency of the system due to reduced transports, as it will be possible to finish a higher number of necessary processes to produce a product in one respective process module.

However, technical and technological restrictions usually constrain the integration of process requirements. The introduced overall static architecture model of the personalized production system and its subjacent decomposition are for that matter open in regard to the number of process requirements and emerging process module types of each class of manufacturing, assembly and transport.

An altogether uncoupled design would only be possible, if the overall system was built exclusively of process module equating production boxes, each capable of every manufacturing and assembly step needed to build a certain product completely in one process module. In such a system, a requirement of transport between value added process module types would be inexistent, eliminating the branch of $F R_{22}$. For the above given restrictions of process integration in one $F R$, this is a highly unlikely setup for a personalized production system. As a consequence, the overall structure model for the personalized production system states a coupled design as standard at the level of personalized production system (i.e. a circled $c$ at the level of module $M_{2}$ in the module junction diagram). 


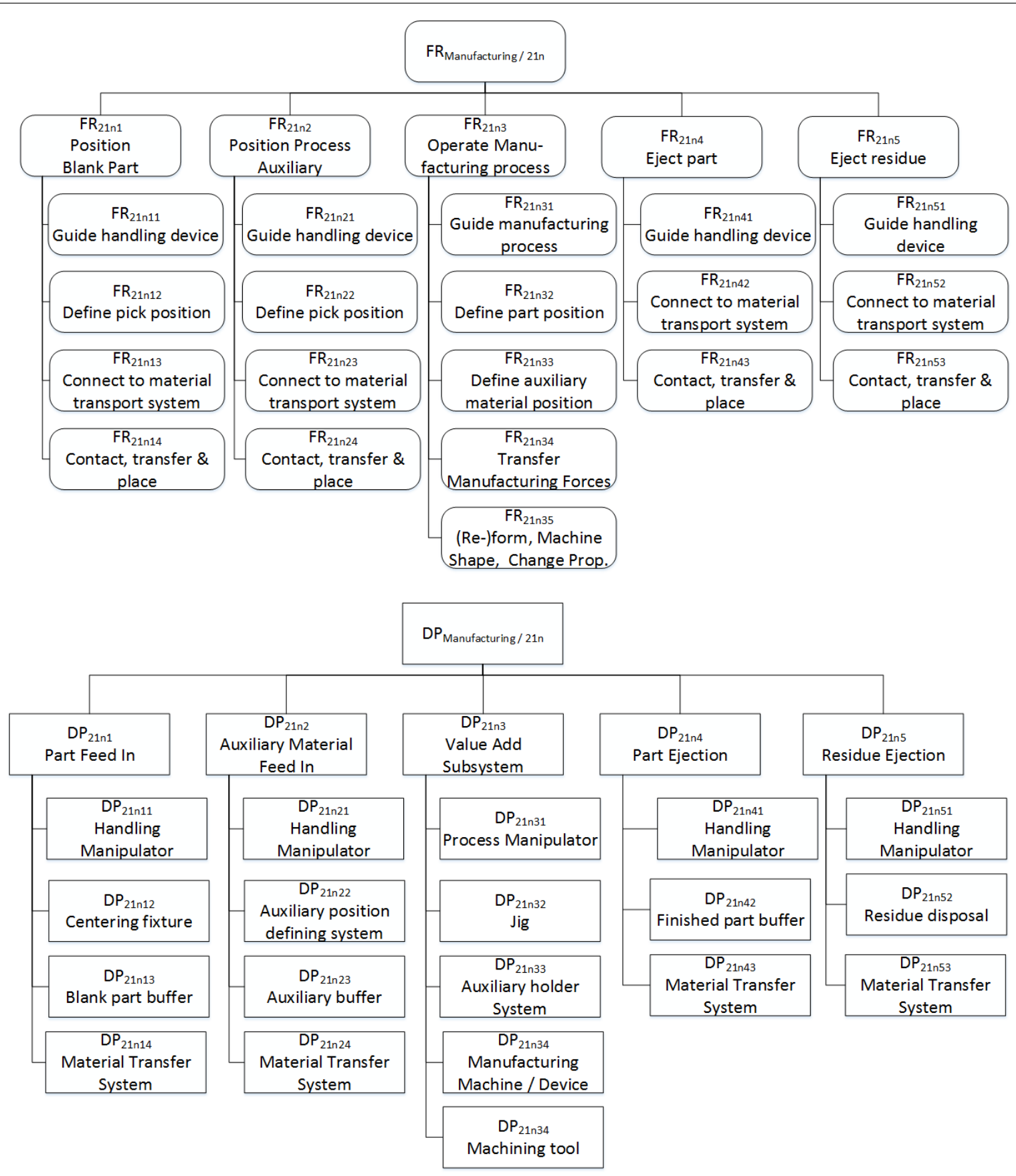

... Functional Requirements FR $\square$... Design Parameters DP

Figure 8. Manufacturing process module decomposition

\subsubsection{Internal structure of process modules}

Further decomposition of the process modules delivers their internal structure model. It serves again the purpose to be used by the planner as a reference template for the system design. The subsystems of the process modules and their interrelation are important for the planning, as they determine the overall function of a process module. It is not necessary to model the process modules in all details. Only the aspects relevant to the segmentation of the overall system structure need to be modeled. That means, the model needs to represent the process module as a system of elements enabling them to perform a process. It is then possible to define the process limitation of the process module with respect to the technical and technological capabilities of its elements and to match the functional process requirements introduced as third-level FRs.

The modeling of the process modules consequently continues the decomposition in the three classes of manufacturing, assembly and transport (Figures 8, 9 and 10). The first decomposition level is decoupled: all FR are in- 


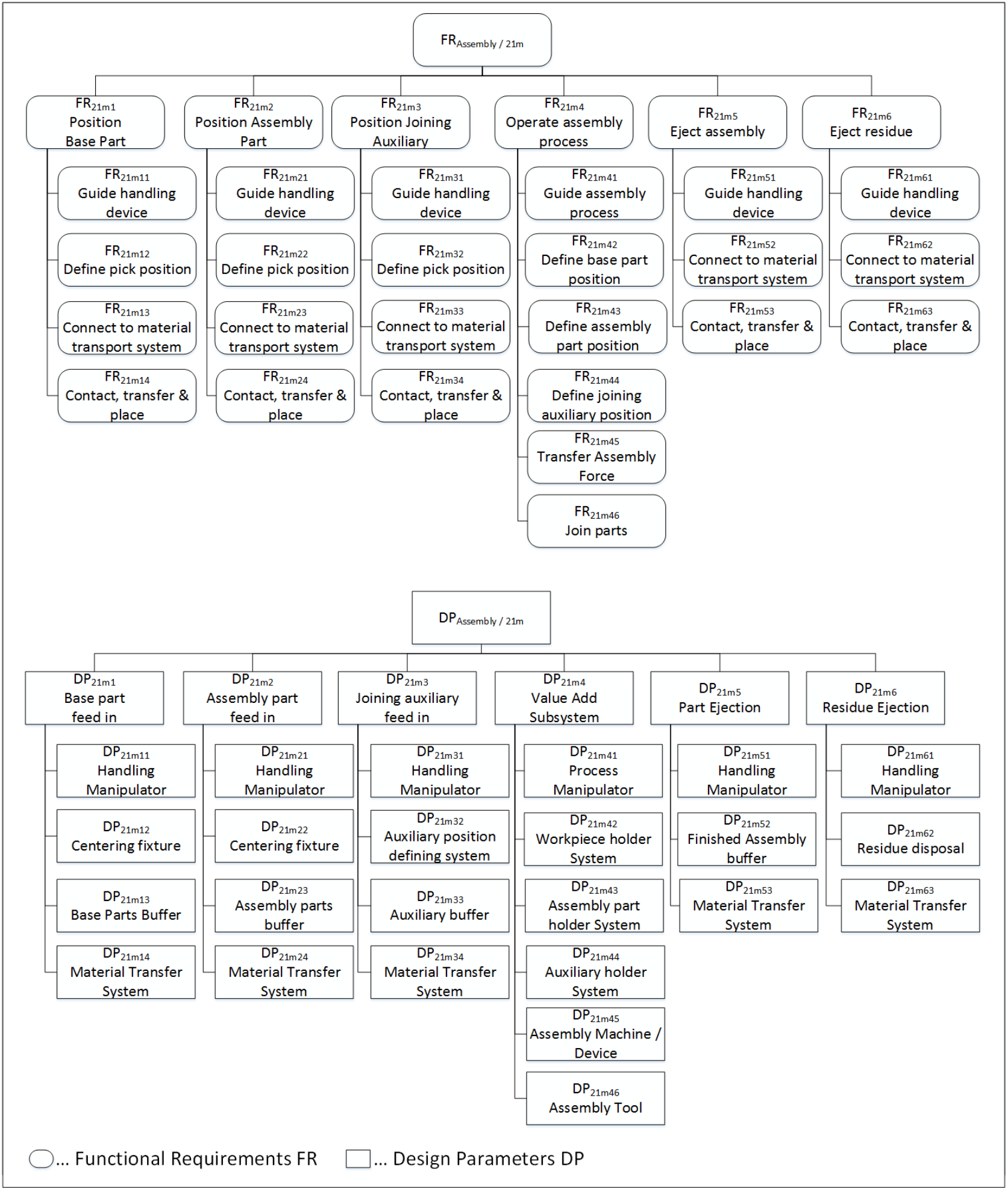

Figure 9. Assembly process module decomposition 


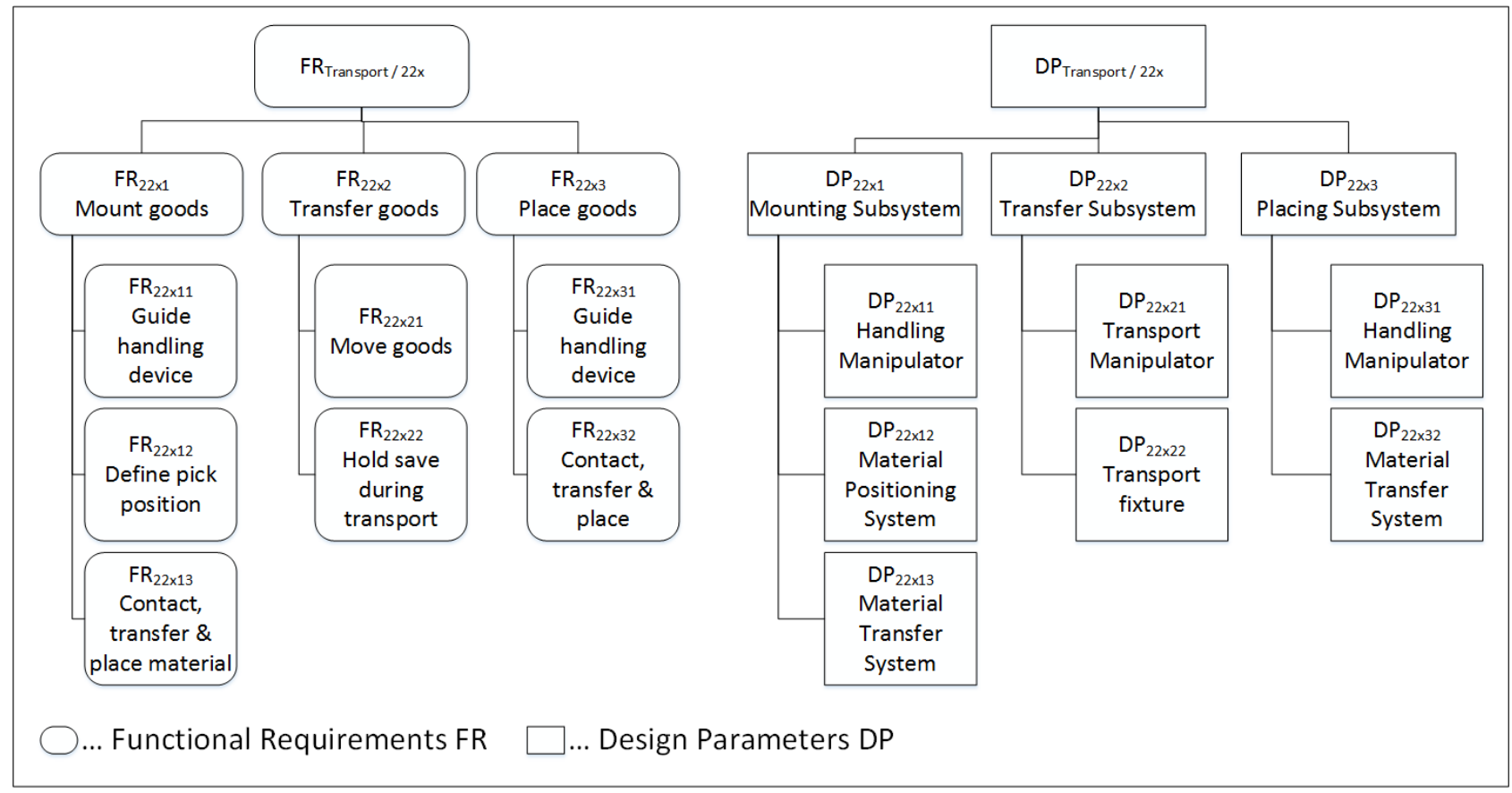

Figure 10. Transport process module decomposition

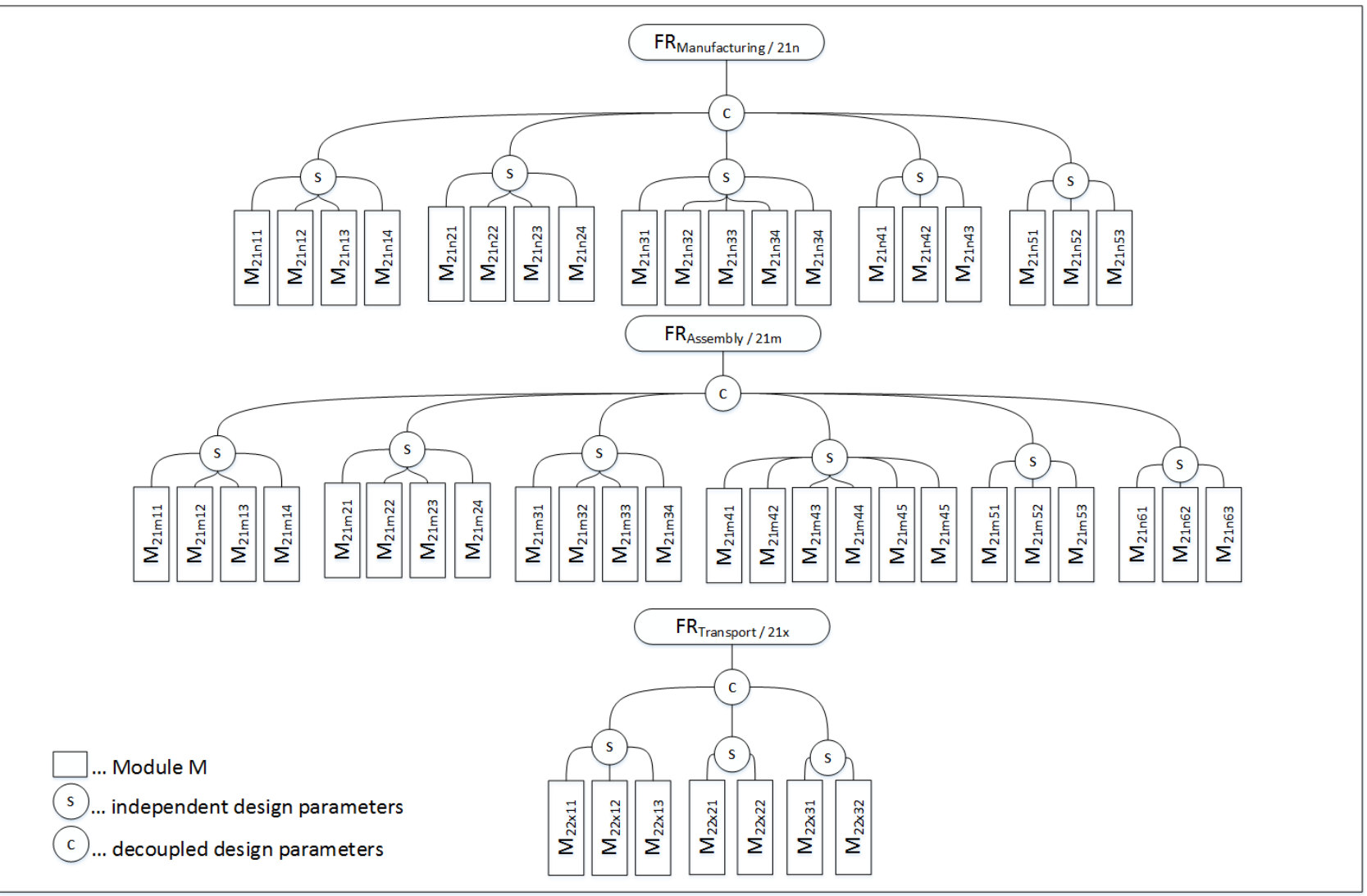

Figure 11. Process modules architecture 


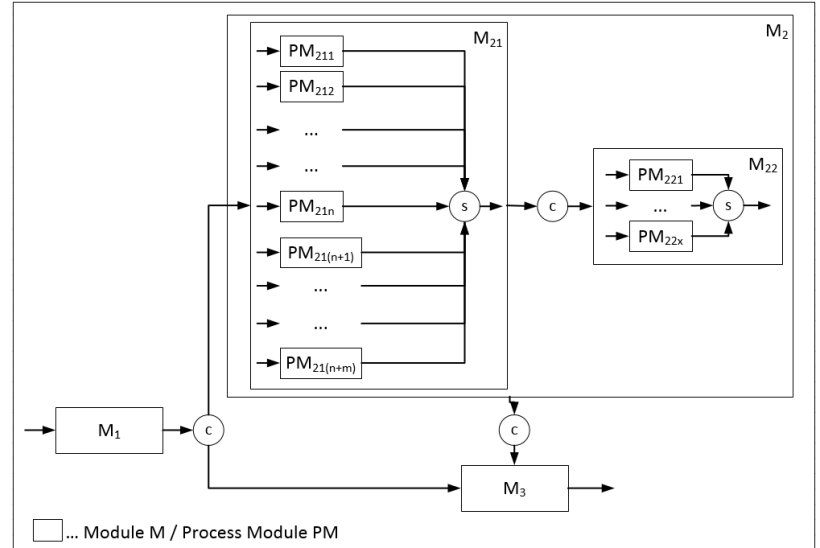

Figure 12. Personalized production system structure flowchart

fluenced by the value added subsystem DP of the modules. At the second level of decomposition, the idealized model states the structure of the process modules to be independent (Figure 11). To strive for a separation of value added and logistical processes to the greatest possible extent, mounting and placing of goods from and to transportation is integrated into the model of the transport module.

\subsection{Generic operational behavior model of a personalized production system}

The process structure of the system is modeled by the flow chart with the system control command (SCC), determining all possible sequences between process modules during operation (Figure 12). The generic SCC holds the availability to couple any value added process modules with each other via transport modules. During operation, this coupling of the value added process modules is of a dynamic nature. The actual dynamic structure of the personalized production system is built through the transport modules that connect value added process modules in terms of flexible routes on demand. The routing depends on the product architecture and the specific process requirements of the produced products (Figure 13). If the product architecture allows for parallel processing, the SCC changes, compared to a sequenced section of product production. The product structure is modeled by means of a precedence graph, connected with the process requirement of each production step needed.

\section{Example Production System Design with the Reference Model}

The generic model of the personalized production system is designed as a master template to be used for personalized production system planning. Models need to be altered and concretized by the planners to their respective use cases, replacing the models' generic by a specific character. Lower-level DPs of the process modules are to be seen as placeholders accordingly, which will be replaced by a specific DPs matching the use case of the planner, thus instantiating the respective process module.

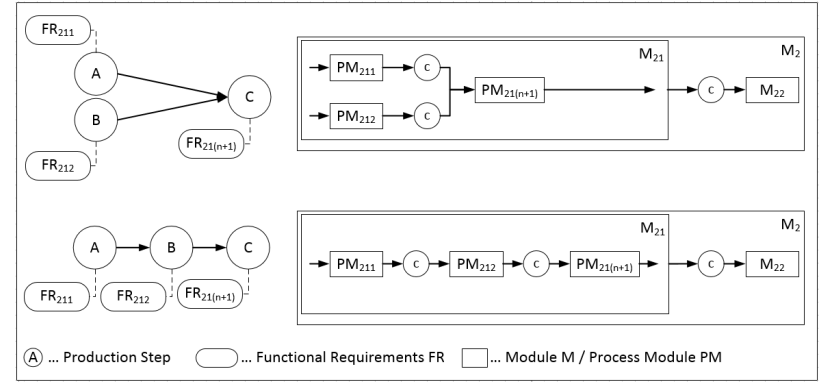

Figure 13. Dependency of product architecture and dynamic production system structure

The reference model is an ideal design. Depending on the actual DPs selected, the system could turn into a decoupled or coupled design. It is the task of the production planner to adapt the system model to the planning case, check for independence during the design process and adjust his planning accordingly.

The respective planning method to instantiate the here presented generic model into an actual production system design is not part of this paper. Nevertheless, an excerpt of an accordingly planned personalized production system design embodiment is shortly described in the following, to make it easier to understand the generic model: The production system of the excerpt was planned for a manufacturer of synchronous motors. The manufacturer offers modular, powerful and dynamic motors, mainly sold to packing machines building industry, that can be configured to individual needs (e.g. power, inertia, brake) and contain customer-individual parts (e.g. length of shaft, type of shaft-hub joint). The company is a rapidly-growing start-up, that continuously adds new product families to its portfolio. With these high uncertainties of volume growth, product variants and customer requirements, a personalized production system was needed.

Figure 14 shows a layout excerpt. Only value added process modules are included to keep the example simple. PM211 to PM220 are differentiated by their functional capabilites. Possible material flows are indicated with the black arrows. Different variants need different functional capabilites and follow different routes through the system. The manufacturing process module PM211 is only utilized if an individualization of the shaft is required.

The box under the layout excerpt lists exemplary the selected DPs for process module PM217. As indicated, not all FR-DP pairings of the generic model are needed. They can be neglected due to product design (auxiliary and assembly part holder) or because the function is part of another FR-DP pairing (e.g. centering fixtures for material supply are not needed with a human handling manipulator). After adaption of the generic model to the plannic case specific requirements, the process module design of PM211 is not an ideal design anymore, as all manipulation activities are performed by the same skilled worker in the workstation. The design is however decoupled, as the manipulations are performed sequentially. The handling manipulators were selected after the value added manipulator was chosen to be a human worker. 


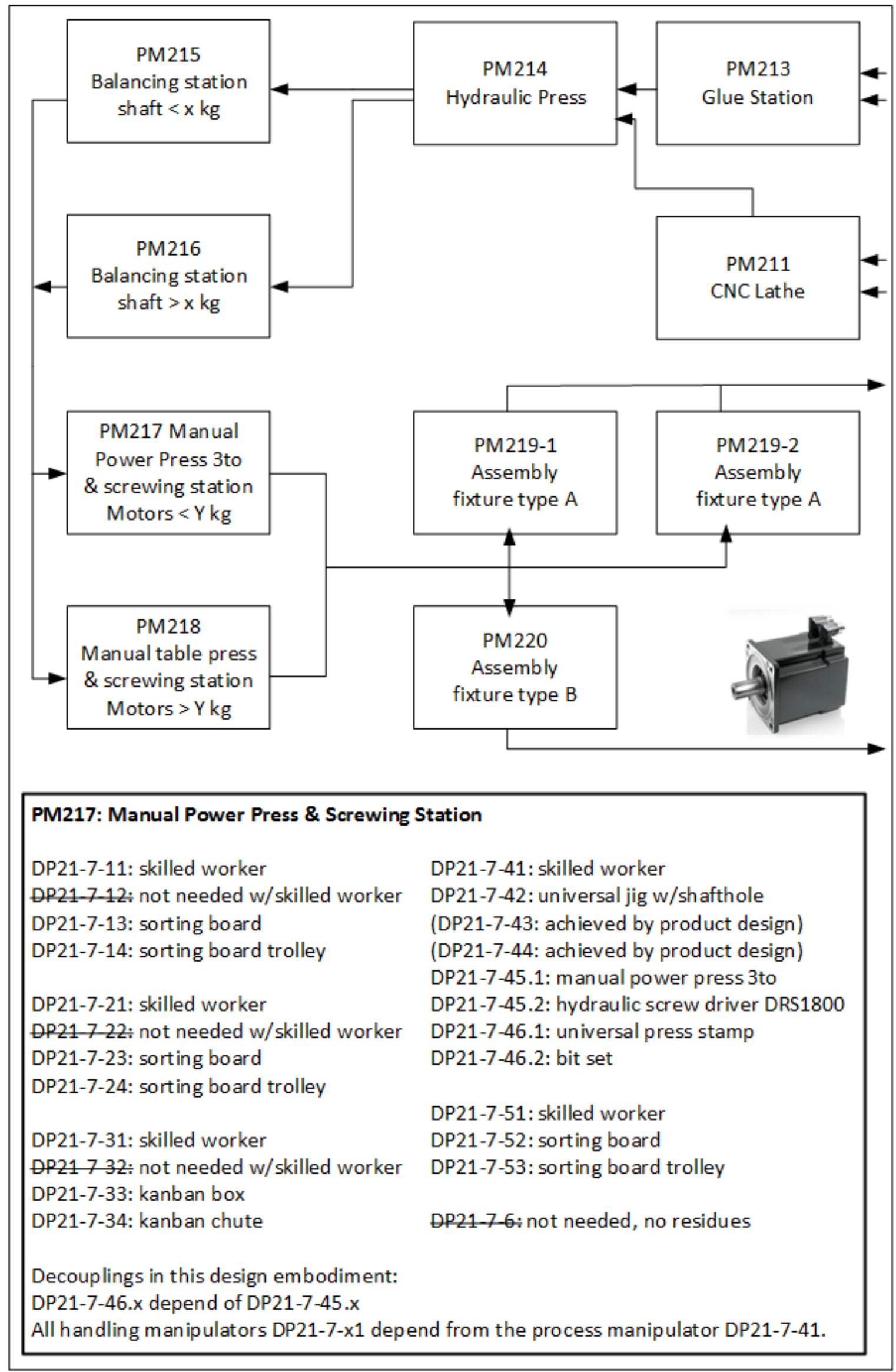

Figure 14. Excerpt of Personalized Production System Design, planned with the Reference Model 


\section{Discussion and outlook}

The here presented generic model represents a personalized production system of flexibly linked process modules. Its inherent routing flexibility maximizes changeability (CR1), as it allows for the processing of various variants of different configuration and even different product architectures. The actual variant capability of the system is determined by the functional capabilities of the system's process modules, which are defined during the system design. A process module may offer only exactly one technology and according technical equipment, to process only exactly one variant. On the other hand, technologically universal process modules are possible. In the case of a process module segmentation purely by technology, a job shop would be an extreme example of the presented model, however operated by lot size one while producing large quantities.

The inherent routing flexibility allows for an ad hoc re-sequencing of the system. In the case of lot size one production, every variant follows an independent route through the system. A new functional period of the system thus starts with every new variant entering the system, with variant specific, functional requirements. Functional periodicity is also possible incident-oriented, with a re-routing in the case of a failure of process modules. The routing can even be re-initialized after each processing step to continually optimize the system during operation. For the latter, live data-driven production control systems are necessary.

It is possible that the system offers more than one process module with the same functional capabilities. Depending on the product architecture, there may also be different operations sequences possible to built a product. These flexibilities of work distribution and operation sequence add new degrees of freedom to production planning and control [38].

The flexible linking makes an independent scheduling of the systems' different process modules possible. There is no uniform, clocked cycle time, but every process module's processing time for a single operation depends on the work content of the processed product variant. Buffers and transportation allow for a continuous work in-process inventory in the system, waiting for processing. A capacity harmonization of the system's process modules should be part of the model instantiation during planning, when the planner decides how many of each process modules are integrated in the system.

The aspect of efficiency, to achieve the topmost $F R$ to produce at the cost of serial production, as well as CR2, is addressed indirectly in the introduced system models of the personalized production system through:

- general segmentation of the system, making a production in efficient lot sizes possible

- a standard of independent value added process modules dynamically coupled by transport modules, enabling the flow within the system

- the model's demand to reduce the total number of different value added process modules types in the system, minimizing transport
Personalized production is per se associated with lot size one. The system structure proposed by the generic model is yet operable with any lot size. The independent scheduling of different process modules even allows for a partial system utilization of a large lot only, however resulting in longer throughput times than during an even call for capacities of the system.

The generic model provides a high-level description of a personalized production system. It ends when it is no longer possible to remain generic. When a process module needs to be actually developed, any last level leaf of the model design tree can be further decomposed. This applies when the instantiation shows that there is no sufficient design solution available on the market to satisfy planning-case specific requirements.

\section{References}

[1] E. Westkämper, E. Zahn, Wandlungsfähige Produktionsunternehmen (Springer, 2009)

[2] Y. Koren, The global manufacturing revolution (Wiley, 2010)

[3] H.A. ElMaraghy, Changeable and Reconfigurable Manufacturing Systems (Springer, 2009)

[4] H. Ulrich, Management (Paul Haupt, 1984)

[5] H. Ulrich, G.J.B. Probst, Anleitung zum ganzheitlichen Denken und Handeln (Paul Haupt, 1995)

[6] H. Stachowiak, Allgemeine Modelltheorie (Springer, 1973)

[7] M. Gessmann, Philosophisches Wörterbuch (Alfred Kröner, 2009)

[8] M.H. Landherr Integrierte Produkt- und Montagekonfiguration (Fraunhofer, 2014)

[9] C. Küber Methode zur Planung modularer, produktflexibler Montagekonfigurationen in der variantenreichen Serienmontage (Fraunhofer, 2017)

[10] K. Ueda, K. Ohkura, Adv. of Intelligent Production (1994), p.75-80

[11] K. Ueda, I. Hatono, N. Fuji, J. Vaario, CIRP Annals 50, 1 (2001), p. 319-322

[12] Y. Koren, M. Shpitalni, J. of Man. Sys. 29, 4 (2010)

[13] Manns, M., R. J. Urbanic, H.A. ElMaraghy, Proceedings of 2nd CIRP on Assembly Techn. and Syst. (2008), p. 2231-243

[14] W. Kern, H. Lämmermann, T. Bauernhansl, Procedia Manufacturing 11 (2017), p. 957-964

[15] W. Kern, F. Rusitschka, W. Kopytynski, S. Keckl, T. Bauernhansl, ICPR Proceedings (2015)

[16] W. Kern, F. Rusitschka, T. Bauernhansl, Procedia CIRP 57 (2016), p. 326-332

[17] VDI5200, Factory planning Planning procedures (Beuth, 2011)

[18] W. Eversheim, Organisation in der Produktionstechnik (VDI 1996)

[19] R. Frisch, Theory of production (Springer, 1964), cited after E. Kahle, Produktion (Oldenbourg, 1996) 
[20] G. Patzak, Systemtechnik: Planung komplexer innovativer Systeme (Springer, 1982)

[21] U. Lindemann, R. Reichwald, M.F. Zäh, Individualisierte Produkte (Springer, 2006)

[22] H.-P. Wiendahl, J. Reichardt, P. Nyhuis, Handbuch Fabrikplanung (Hanser, 2014)

[23] E.-F. Schimke, R.-D. Hoeschen, TZ für praktische Metallbearbeitung 71, 6 (1977)

[24] E. Frese, Organisationsstrukturen und Managementsysteme, in [25]

[25] W. Eversheim, G.Schuh, Betriebshütte: Produktion und Management (Akademischer Verein Hütte, 2014)

[26] G. Wöhe, U. Döring, Einführung in die Allgemeine Betriebswirtschaftslehre (Vahlen, 2000)

[27] T. Petersen, Organisationsformen der Montage (Shaker, 2005)

[28] H.-J. Bullinger, Systematische Montageplanung (Hanser, 1986)

[29] G. Ropohl, Allgemeine Technologie (KIT Scientific Publishing, 2009)
[30] A. Specker, Modellierung von Informationssystemen (vdf, 2005)

[31] W. Eversheim, F.-L. Krause, Produktgestaltung, in [25]

[32] N.P. Suh, Axiomatic design (Oxford University Press, 2001)

[33] T. Nebl, Produktionswirtschaft (Oldenbourg, 2011)

[34] G. Siegel, Mass Customization (VDM Dr. Müller, 2008)

[35] D. Spath, M. Weck, G. Seliger, Produktionssysteme, in [25]

[36] W. Kern, Handwörterbuch der Produktionswirtschaft (Schäffer-Poeschl, 1996)

[37] N.P. Suh, A Theory of Complexity, Periodicity and the Design Axioms, Research in Eng. Design, 11 (1999)

[38] H.-H. Wiendahl, P. Foith-Förster, C. Fries, Pla nung zukünftiger Automobilproduktionen, in [39]

[39] T. Bauernhansl, M. Fechter, T. Dietz, Wandlungsfähige Automobilproduktion - Ansätze für eine zukünftige Produktion ohne Band und Takt (in publication) 